This is the accepted version of the following article: "Distinctive Approaches to Computer Graphics Education", which has been published in final form at https://onlinelibrary.wiley.com/doi/abs/10.1111/cgf.13305.

This article may be used for non-commercial purposes in accordance with the Wiley Self-Archiving Policy

[https://authorservices.wiley.com/author-resources/Journal-Authors/licensing-open-access/open-access/self-archiving.html]

\title{
Distinctive Approaches to Computer Graphics Education
}

\author{
B. Sousa Santos ${ }^{\dagger 1}$ J.-M. Dischler ${ }^{2}$ V. Adzhiev ${ }^{4}$ E.F. Anderson ${ }^{4}$ A. Ferko ${ }^{7}$ O. Fryazinov ${ }^{4}$ M. Ilčík ${ }^{6}$ \\ I. Ilčíková ${ }^{7}$ P. Slavik ${ }^{5}$ V. Sundstedt ${ }^{3}$ L. Svobodova ${ }^{5}$ M. Wimmer $^{6}$ J. Zara ${ }^{5}$ \\ ${ }^{1}$ DETI/IEETA, University of Aveiro, Portugal \\ ${ }^{2}$ University of Strasbourg, France \\ ${ }^{3}$ Blekinge Institute of Technology, Sweden \\ ${ }^{4}$ The National Centre for Computer Animation, Bournemouth University, UK \\ ${ }^{5}$ Faculty of Electrical Engineering, Czech Technical University in Prague, Czech Republic \\ ${ }^{6}$ Institute of Computer Graphics and Algorithms, TU Wien, Austria \\ ${ }^{7}$ Faculty of Mathematics, Physics and Informatics, Comenius University in Bratislava, Slovak Republic
}

\begin{abstract}
This paper presents the latest advances and research in Computer Graphics education in a nutshell. It is concerned with topics that were presented at the Education Track of the Eurographics Conference held in Lisbon in 2016. We describe works corresponding to approaches to Computer Graphics education that are unconventional in some way and attempt to tackle unsolved problems and challenges regarding the role of arts in computer graphics education, the role of research-oriented activities in undergraduate education, and the interaction among different areas of Computer Graphics, as well as their application to courses or extra-curricular activities. We present related works addressing these topics and report experiences, successes, and issues in implementing the approaches.
\end{abstract}

Categories and Subject Descriptors (according to ACM CCS): K.3.2 [Computers and Education]: Computer and Information Science Education-Computer science education, Curriculum

\section{Introduction}

As Computer Graphics (CG) and related fields rapidly expand and evolve, designing and maintaining appropriate and updated curricula, as well as teaching methods is more and more demanding and should be approached as a continuous research activity. Research in CG education occurs mainly around the two following topics: 1) pedagogy and practice of teaching CG and related technology, as well as 2) the set up of new and specific curricula, often in relation with other curricula, such as art and design. The major challenge in this conext is teaching students state of the art knowledge from various different fields (computer science, numerical mathematics, geometry, visual analytics and esthetics, game technology, arts, etc.) and to apply it in a scholarly way, i.e., consistently with the curricula and knowledge level of

\footnotetext{
$\lceil$ Authors, except the first and second, are listed in alphabetical order of their surnames
}

the students. This paper was written as a collaborative endeavour by the Education Papers co-chairs and the authors of four full papers featured in the EG2016 programme, all providing reflections on approaches to address the previous challenge. These approaches, unconventional in some way, tackle the following questions: What is the role of arts in graphics education, and how can they be introduced in technically-oriented computer graphics courses? Will the interaction among different areas of computer graphics be advantageous, and how to implement it, namely a visualisation course in a game development curriculum? What is the role of research-oriented activities in undergraduate education, and how should they be managed with an appropriate balance, in curricular and extracurricular activities? The paper's objective is to present experiences of educators concerning these topics and to analyse learning outcomes of the proposed unconventional teaching practice. It is organised as follows: Section 2 addresses previous work related to each of the topics; Section 3 describes a course offered at Czech Technical University in Prague (CTU) providing 
technically-oriented students a key insight into art they may apply to their further education in various CG courses; Section 4 describes the design and running of a visualisation course targeted at students attending degree programmes in digital game development; Section 5 provides insights into an undergraduate research course for final year undergraduate students embedded in a UK undergraduate degree programme in the CG, animation and effects field; and Section 6 gives an overview about the Central European Seminar on Computer Graphics (CESCG), an annual scientific seminar for undergraduate students of visual computing having as main mission to promote computer graphics research and to motivate students to pursue academic careers.

\section{Related Work}

$\mathrm{CG}$ as a field of Computing has characteristics common to other fields; however, it has specificities that have an impact on the education of experts. While CG education covers a broad range of topics, one issue very specific to CG is its strong link with other domains. Here, our focus is on relations with Arts and Game technology. Another issue that we are concerned with is teaching students knowledge in a scholarly way adapted to the their level (undergraduate or graduate). In this context, we review the specific role of a research component in $\mathrm{CG}$ education.

\subsection{CG education in relation with Arts and Game technology}

The idea of combining arts and CG is not a new one. In university curricula around the world, several attempts have been made to merge the worlds of CG and art. There were several efforts to combine CG and art where the graduates were able to communicate properly with "both worlds", e.g., in special study programmes like [O1199, BA06, Ebe00, OC00, CMA10, CD02] and some others. At Czech Technical University in Prague, an alternative approach was selected: creation of a specific art based course that in combination with other courses (e.g., Human-Computer Interaction courses) will give sufficiently deep insight into the world of art for CG students. This approach can work well for universities without sufficient teaching staff in art and related disciplines. This concerns mainly small universities and universities of technology.

Similarly to arts, there is a long standing relation between CG and Game technology, but the relation between Visualisation and Game technology is less obvious. Courses in Visualisation are often found as part of a computer science curriculum to gain new insights and understand complex data effectively. Concepts in visual analytics, scientific and information visualisation can be of great importance when applied to digital games. Since computer games of today generate more data than ever it is vital to educate game development students with the theory and practice of data visualisation. Game analytics, for example, is an important topic in business intelligence [NDC13], and it can be used to educate and motivate players [Haz14]. It is also important for developers to make game design decisions [ALA*10]. Tracking and analysing behavioural data from games [MeNS11, WKG*14, MBWMN14, FCD*15], or the increase in eSports, has also made the topic more relevant [KWP14]. Significant existing resources are focusing on visualisation techniques [Sun16], but the emphasis on a visualisation course for a game programme was lacking. Due to the increased interest in game analytics and eSports, game visualisation research [BEJK12, NDC13, Haz14, KWP14], has grown in the last few years. There have also been recent educational developments in how a visualisation course curriculum should be structured which are relevant to this work [The13, Dom15].

\subsection{Practice of teaching: research components in CG education}

Just as many undergraduate computing degree programmes include Visualisation courses, many also have for some time included some research components, often to satisfy industry demands for graduates with research skills. This is especially true in the case of the creative industries [LH11], where Research and Development (R\&D) is a significant part of modern life of practically all companies whose main business is CG and its applications, such as visual effects. In many cases the research component offered to students are synonymous with and limited to capstone courses, such as final undergraduate dissertation projects [WS06, BBD*10, Eyi11]. The type of research skills employed in the creative industries, however, tend to favour collaborative research [Shn16].

Guidance, promotion and presentation of student research at BSc and MSc level is another important topic to deal with. The Central European Seminar on Computer Graphics (CESCG) [HFSK00] connects CG students from around 15 universities across Europe. An international team of scholars leads students in the last phase of their research work, through the whole publishing process up to the final presentation at the seminar. The unique concept constantly evolves and adapts to the innovations in CG and education.

\section{Arts for CG Students}

Computer graphics penetrates into many activities of everyday life and new technologies in the field of computer graphics open up new prospects for artists. Traditionally artists learned some basics of computer graphics from CG experts and this knowledge was used by artists for the creation of artefacts with CG flavour As the complexity of CG tools is increasing and also the complexity of artworks is increasing as well, it is necessary to involve CG experts into creative processes of art.

The problem is that CG experts usually have no appro- 
priate insight into creative processes performed by artists. This creates an obstacle in communication between artists and computer graphics experts. A solution to this problem is to train CG experts in the field of art (at least to a certain extent). At CTU, there is a successful course of this kind (under the name Art and Graphics Design) that has been running for the past 7 years [SSZ16]. The course has been taught by Lucie Svobodova, a co-author of this paper. She is a practising artist with an impressive record of art activities - her works are featured in important art collections in the Czech Republic. Within the course she continuously presents an artist's point of view on creative processes used.

Whereas CG students at CTU are primarily taught in a number of technically oriented courses how to create graphics software, this course provides them with a key insight into art. As the presented course is included in a BSc programme, students are early acquainted with artistic ways of creation in order to apply this acquired knowledge to their further education in various CG courses included within the following MSc programme. The course is scheduled for 14 weeks, consisting of 2 hours of lectures and 2 hours of seminars (where students mostly draw) per week, which corresponds to 5 credit points in the European Credit Transfer System (ECTS).

\subsection{Art and Graphics Design Course Structure}

The innovative approach used in the Art and Graphics Design course is based on the concept of immersion into art. This concept consists of two basic components:

A. "Forcing" CG students to feel and think like artists during the creation of a piece of art.

B. Giving them a basic idea regarding the concept of art in general.

Part A is based on the following assumption: the creative processes are of universal nature regardless of whether the work of art is created using traditional means (pencil, brush, chisel, etc.) or by some tools based on CG technologies. In our educational process the effort has been concentrated on the area of drawing, using charcoal as a medium. The general opinion among artists is that charcoal is especially suitable for beginners as it provides fast and visually appealing results.

The process of drawing may be characterised as the transformation of 3D information to $2 \mathrm{D}$ which may remind $\mathrm{CG}$ students a kind of synergy with mathematics. The aim of the drawing process is to show the aspects of the transformation process in all its complexity from the artist's point of view. Students start by drawing simple objects - at first a planar one, continuing with non-planar ones and ending up with complex objects such as human bodies. The drawing of basic objects allows the students to get an idea about the properties of light, as well as to get a feeling for the structure of a 3D scene (Figure 1). Students are acquainted with art concepts that create aesthetically pleasing effects for the viewer. The main concept delivered is the rule of the golden ratio. This rule creates an interesting link between mathematics and art. Such an approach helps to stimulate students in a multidisciplinary way of thinking, including a visual one. As the number of drawings they should draw during the course is 12 , they get hands on experience with creative processes performed by artists.

Part B of the concept of immersion into art deals with more abstract issues in the field of art. There are two parts to this effort:

- Showing students how respected painters used the techniques learned (this way students can see the application of these techniques with much better results than they could achieve - thus, they can better understand why these techniques were developed and used).

- Showing students applications of these drawing techniques in an environment they are familiar with - some applications in the CG industry (this way they will be convinced that the approach taught may be of significant importance in the CG industry).

The first point is covered by a guided tour of the National Gallery in Prague, where pictures of various styles drawn in various periods of time are on display. Another educational activity is a lecture in which students become acquainted with basic historical styles. These styles are demonstrated in an entertaining form: video sequences from movies where these styles appear. The second point is linked up with applications familiar for students like web design etc. where application of the art techniques taught is adequately demonstrated.

\subsection{Experience gained}

The interesting issue of the approach described lies in the concept of immersion into art as stated above. Providing information about the nature of creative processes, students can better understand the individual phases of artistic ways of thinking and doing.

We consider the course successful. There has been very positive feedback from students together with a positive reaction from students and teachers in follow-up courses in the field of CG. At CTU there is a standard procedure based on a standard questionnaire (filled in by students) by means of which all courses are evaluated statistically. The evaluation metric that has been used for years is the same for the entire university and as such it is considered trustworthy. The course mentioned was always evaluated very positively - the course was always in the top 5\% in the list of all courses given at Faculty of Electrical Engineering (about 700 courses were evaluated each semester). There have been also many projects in which CG students and art students have come together. The feedback about the communication 


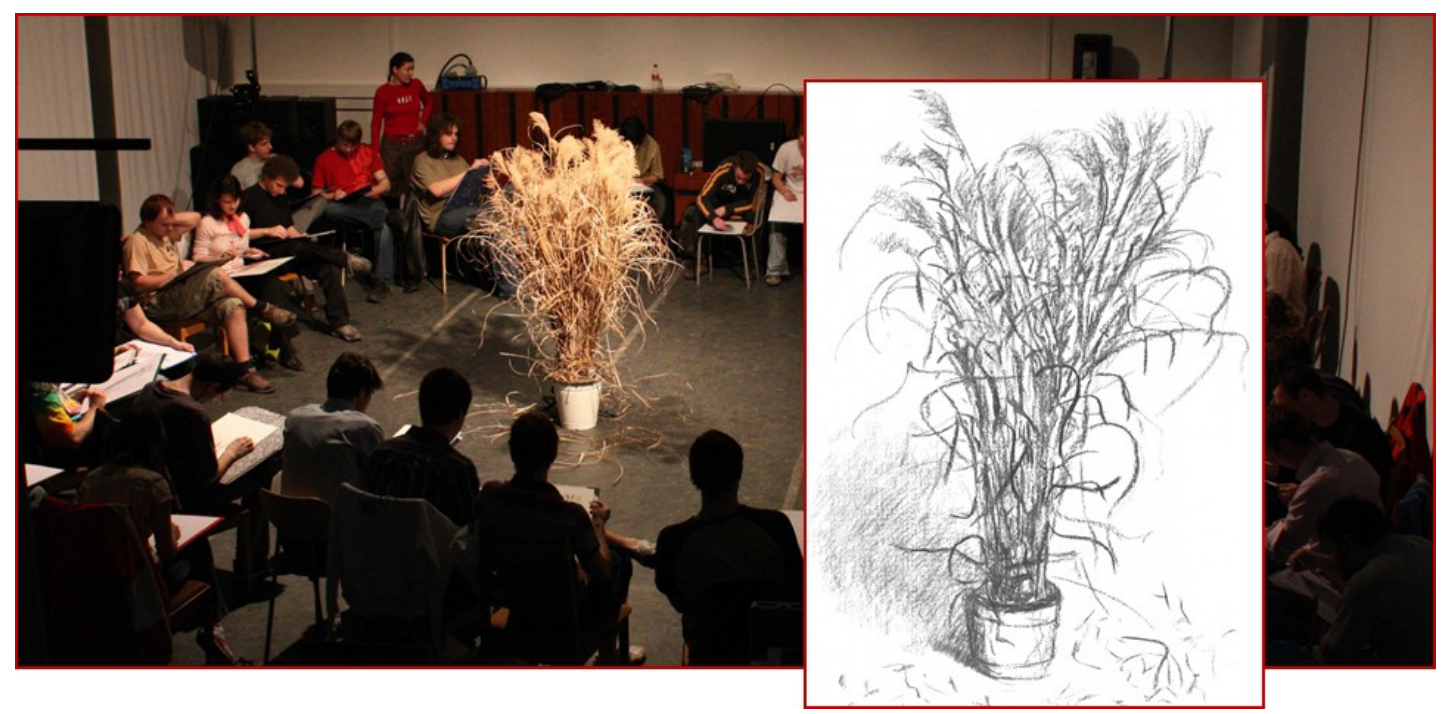

Figure 1: CG students during their creative work.

with artists was gathered in an informal way (which, in our opinion, does not diminish the overall positive impression that the course has generated).

There is also another benefit of the course - CG students are able to design and develop new graphics tools for artists in close cooperation with them. As they can better understand the requirements of artists these new tools are of very high quality and are tuned to specific artistic needs. Some good examples from the field of movies, animation, and image processing are described, e.g., in [LFB ${ }^{*} 13$ ].

The main advantage of the course is its compactness. Such an intensive, one semester course is very time-efficient compared to extensive study programmes in which the topic (artistic creation) is spread throughout several courses. The current form of the course is a result of several years' effort in which a good balance among the individual components of the course was achieved. In the future we are going to run the course in its current, finely-tuned shape. More details of the presented course can be found in [SSZ16].

\section{Visualisation in a Game Development Curriculum}

This course is part of a five-year degree at Blekinge Institute of Technology (BTH) and was created due to the increasing importance of visualisation theory and practical knowledge about visualisation tools in the area these students are going to be working in. It is based on concepts addressed in traditional visualisation courses while being complemented with assignments carried out in a research laboratory. The learning objectives of the course are based on experiences from traditional visualisation courses as well as the fit of the programme goals. Novel aspects are that several assignments focus on visualisation techniques for games, as shown in Figure 2, and eye tracking technology has been used to generate data from games [Sun16].

\subsection{Visualisation Course Structure, Advantages, Disadvantages, and Equipment}

The course is at a computer science basic level (corresponding to undergraduate level), has been taught both in the third and fourth year of the programme, and corresponds to 7.5 ECTS credits. The structure of the course includes lectures, computing labs, supervision, individual and group project work, presentations of students'work, reading scientific literature and using it practically within the assignments. It has an eleven two-hour lecture series at the beginning (so focus can be on the larger visualisation project at the end) addressing the following subjects: (L1) Visualisation Introduction, (L2) Perception and Cognition, (L3) Colour, (L4) Data Representations, (L5) Information Visualisation, (L6) Scientific Visualisation, (L7) Data Collection and Gnuplot (+Lab 1), (L8) Visualisation Techniques in Games, (L9) Academic Writing and LaTeX (+Lab 2), (L10) Eye Tracking in Games (+Lab 3), and (L11) Project Description. Academic writing and LaTeX were introduced in the course so that students could put their visualisations into a framework, which is useful to prepare them for the final thesis work.

In Assignment 1, the students find more and less effective examples of visualisations. They should also redesign the poor examples into more effective visualisations in the same way as the assignment presented in [Agr07]. The results are then discussed in a seminar. In Assignment 2 students generate data and use LaTeX and Gnuplot to have a framework for publishing high quality and effective visualisations. Assignment 3 focuses on analysing existing game data visualisation 

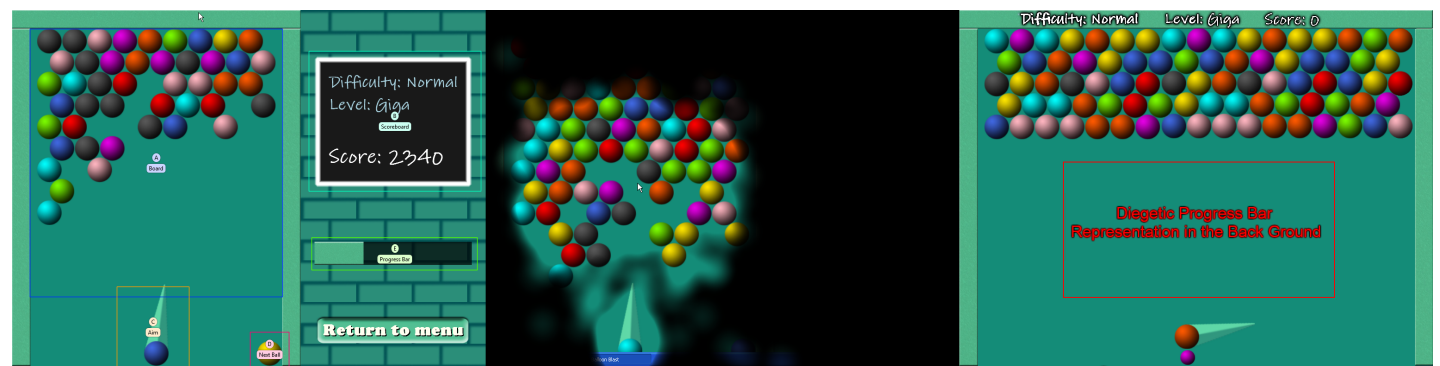

Figure 2: Example project from [Sun16] exploring what interface elements are used and important for the game experience: (left) original game with areas of interest used in the eye tracking analysis, (middle), transparent heat map of attended areas, and (right) redesigned game based on the analysis. Image courtesy of Kim Restad, Max Danielsson, and Alexander Vestman.

techniques based on the recommended reading material, the lectures, and their own ideas. In Assignment 4 an eye tracker and software are used in a research laboratory to create visualisations. Eye tracking was later an option for the students to generate data for the assignment. Although this exercise is individual work, one benefit is that data gathering can be carried out in groups, and the students can later work on the analysis with non-recording licenses of Tobii Studio in their own time. In Assignment 5, a group project, students focus on a particular area of interest more deeply. This assignment is based on a research question that the students aim to answer with the help of visualisation techniques and it includes generating relevant data.

More detail on the lectures and the assignments can be found in [Sun16]. The assignments increase in complexity along the course. This implies that in the later stages of the course students need deeper reflections, more parallels drawn as well as an additional relation of their work to the scientific literature. Regarding the cost and equipment for running the course, it scales well depending on the number of students. Several of the assignments are individual reports, and they do require a significant amount of evaluation. Other parts are in groups of students for example laboratory sessions, seminars, and project supervision. This particular setup requires a low-cost eye tracker and the Tobii Studio license. Using this technology is one example of data generation and other tools could be used for gathering and visualisation. Eye tracking was chosen due to the novelty of the technology being incorporated into games.

\subsection{Experienced gained}

It was interesting to follow the students'work evolution as the complexity increased. From the beginning, they managed to identify good and bad visualisations, but as the course went on more relevant visualisation terms, techniques and concepts were used. These ideas include issues in perception, cognition, colour, visualisation algorithms, etc. From running the course, it was seen that topics in traditional visualisation courses are relevant on game develop- ment programmes. Although the material might need to be made more concrete and with an increase in research and development in visualisation and games, the course curriculum could be targeted with further game examples. It would also be interesting to accompany the lecture series with guest seminars from industry discussing visualisation, telemetry, and game analytics. To differentiate the course from traditional visualisation courses perhaps it could be renamed to "Visualisation in Games". Since it is based on what is traditionally taught it might be too broad, trying to cover too many aspects. Some students liked the design aspects and others wanted it more data oriented. The course does have a significant amount of report writing and some students felt challenged by the time it consumed. Some assignments could be carried out more efficiently by providing existing data sets. The course has currently a heavy focus on writing scientifically as part of the assignments. Although it is very important for students on technical degree programmes to practice academic writing, perhaps additional focus could be better spent on creating interactive visualisations in game environments.

Some students found using the equipment in the research laboratory particularly interesting and that the course was current as a positive aspect. If it fits to have LaTeX in an earlier part of the programme, this would also be recommended. This could also benefit other courses to improve the quality of student report writing earlier on. Students reported the course to have clear grading criteria which were appreciated since they knew what to expect. However, there is a lack of a relevant course book in the area of visualisation and games. There is one book focusing on game analytics [NDC13] but a textbook directed towards students might be more suitable in the context of the curriculum. Since new technologies are applied to games, including eye tracking, there is a great potential and challenge in the gathering and visualising this vast amount of data in the future. It is therefore important to prepare students on game development programmes with the appropriate skills in this expanding area. 


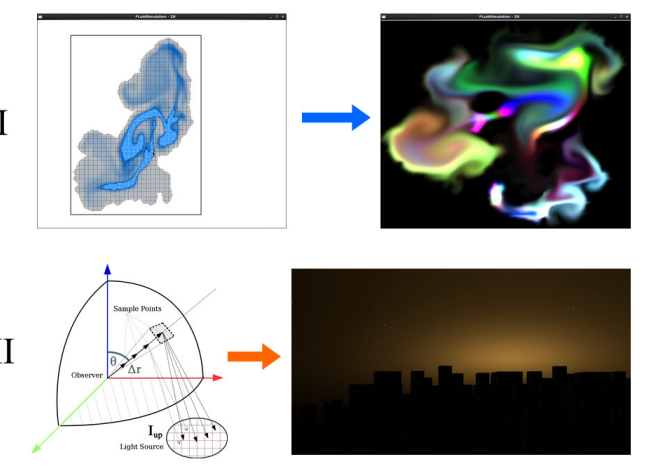

Figure 3: Results from two projects completed in the CRP course. I is an optimized grid-based fluid simulation that considerably reduces the amount of data being processed at each simulation step [ALFA15]; II extends existing nighttime illumination methods by integrating light pollution from artificial light sources [MPA16].

\section{Computer Graphics \& Animation Undergraduate Research Projects}

The R\&D-oriented Collaborative Research Project (CRP) [AAF16] is a mandatory research course (worth 20 credits/10 ECTS credits) that students take in the first semester of the 3rd (final) year of the BSc (Hons) Software Development for Animation, Games and Effects (SDAGE) programme of the National Centre for Computer Animation (NCCA) in Bournemouth University's Faculty for Media and Communication. At its heart the SDAGE programme is a computer science/software engineering degree programme with a heavy emphasis on computer graphics (CG) techniques used in the creative industries, and like the other degrees of the NCCA's computer animation framework it subscribes to the NCCA's philosophy of "Science in the service of the Arts" [CMA10].

The CRP course is a separate course from the programme's dissertation project and includes teaching and learning focussed on the nature of collaborative research [Shn16] and development, especially in small teams, as encountered in the creative industries dealing with computer graphics, computer animation and game development. The rationale for a dedicated research course in the SDAGE undergraduate programme is to counteract the emphasis on vocational skills for employability in industry that is unfortunately common for many undergraduate programmes that cater for the creative industries. This emphasis pertains despite the actual needs of employers, as can be seen in the case of the computer game development and visual effects industries who expect that universities produce graduate software developers with not only vocational but also with rather advanced research skills [LH11].

\subsection{CRP Course Objectives}

The aims of the CRP course and its learning outcomes are that after completing the course, students should be able to demonstrate the ability to research and develop a software artefact solving a CG research problem (Figure 3). A positive side effect, apart from benefiting students in terms of learning and professional development, is that engaging undergraduate students with the type of research more commonly encountered in postgraduate research programmes tends to engage the high achieving students that would otherwise disengage due to a lack of challenge and therefore serves as a complement to the usual educational practice of improving the learning of weaker students $\left[\mathrm{CWF}^{*} 10\right]$. In the CRP course the major challenge for students is to deliver not just a software artefact but also a report in the form of an academic paper describing their problem solution by working effectively as part of a team while planning, managing and delivering the project in the given timespan. The course is driven by the largely student-led project, supported by lectures, regular tutorials and frequent seminars, and consequently matches the activity-led instruction sequence [ $\left.\mathrm{APH}^{*} 12\right]$ fairly well. As such, this course could also be considered an example for teaching computer science in context [CC10], focussing on CS research methods in the context of CG research.

\subsection{Running the CRP Course}

The research project that the students work on is set by members of the NCCA's faculty. Faculty members who may take on the role of project tutor and collaborator must carefully prepare briefs for suitable small-scale projects for the course that address a real-world problem, are within the scope of their own research and are both challenging enough and at the same time achievable in the available time-frame and at the skill level of final year undergraduate students. The course itself is organised in two parts that begin at the same time, running in parallel for the first month of the project. The first part is concerned with background and theoretical aspects of research and is delivered as a short series of five lectures [AAF16] that introduce students to the methodology and the practice of research, with particular emphasis on the specifics of the Computer Graphics, Animation and Games fields, illustrated with concrete examples from both academia and industry. Students are introduced to the scientific method and its aspects seen through the prism of a research process, effective literature search strategies and the main principles of research ethics. To provide them with a solid grounding for the report they will have to write about their project they are also taught academic writing and presentation techniques. The second part of the course is the research project, which the students have to choose at the beginning of the course from a list of available project briefs. Their work on these is supported by weekly tutorials with a collaborating faculty member and four two-hour 
long student-led seminars, in which students present their project progress and discuss this with the remainder of the cohort and their tutors. These are scheduled throughout the course, to provide an opportunity for students to further develop their personal and communicative competences. After submission of the coursework there is a final seminarlike session in which the students present the results of their project to members of the faculty and the other students of their cohort.

\subsection{Assessing the Collaborative Research Project}

Students submit the software artefact, a portfolio consisting of supporting documentation (meeting notes, system specifications, design documents etc.) and the report in the form of an academic paper as a single coursework element for assessment. The weighting of the grade is $50 \%$ for the students' individual contribution to the artefact and $50 \%$ for the students' individual portfolio, including the individual contribution to the project report/paper. From the grading academics' point of view, the assessment of the projects is similar to the reviewing of conference submissions, taking into account the fact that the students are undergraduates without previous research experience. A 'first class'(in the grading guidelines of the university defined as achieving a mark of $70 \%$ or above) award is made to projects that are deemed to be publishable by the supervising faculty members.

\subsection{Experience gained}

The greatest strength of the CRP course is that it engages undergraduate students in the type of research more usually experienced at postgraduate level. The course, which has so far had four iterations, has been fairly successful in terms of proportion of student projects resulting in submissions and publications, with students successfully submitting their work for presentation at UK undergraduate research conferences (including the British Conference of Undergraduate Research in 2016 and 2017 - http: / / www . bcur . org) and several successful submissions to established CG conferences (e.g., [ALFA15, MPA16, MMA17]) (Figure 3). However, as Baldwin et al. [BBD*10] note, engaging undergraduate students in research is often constrained by university resources and unfortunately "the extent to which a department can offer [...] student-faculty research is determined by the availability and interests of potential faculty supervisors". This is counter-balanced with the possibility to collaborate with students on a publication based on a successful project, which serves as an incentive for faculty members to act as supervising tutors [AAF16] and as an incentive for students to do well, resulting in an overall rewarding and positive experience for everyone involved.

\section{Research Seminars in Undergraduate Programme}

The Central European Seminar on Computer Graphics (CESCG) is an annual scientific seminar for undergraduate students of visual computing from all of Europe [IIFW16]. Its main mission is to promote graphics research and to motivate students to pursue academic careers. The seminar usually takes place in April in Smolenice, Slovakia. During three days students from about 15 universities present their first scientific research to an audience of approx. 80 students and professors. The scientific programme is supplemented by workshops focused on academic skills and career planing for young researchers. Interactive sessions on innovation help them to increase the value of their ideas. A half-day EXPO bridges industry and academia. It provides a lot of inspiration to the students through interaction with the latest technologies and personal contact with top experts in visual computing.

\subsection{How it started}

Bilateral Joint Seminars had been organized by the Graphics departments of the Comenius University in Bratislava and TU Wien. Growing interest of other research groups inspired Helwig Hauser and Andrej Ferko to organize an international conference-like event for undergraduates. The first CESCG was held in 1997 jointly in Vienna and Bratislava [HFSK00, WFSKH06] with student contributions from Budapest, Prague, Brno, and Graz.

The organisers have always shaped a tradition of a unique event. The seminar is regularly held in the Smolenice castle (Figure 4). All attendants are accommodated in the venue, enclosed by beautiful nature, but still at the periphery of a small town. Such setting stimulates networking between students who can share insights into their research with similarminded people. Retention of those participants who later become academics supervising their own students is essential for the sustainable organization of CESCG. Participating at CESCG became a popular part of the culture at many institutions.

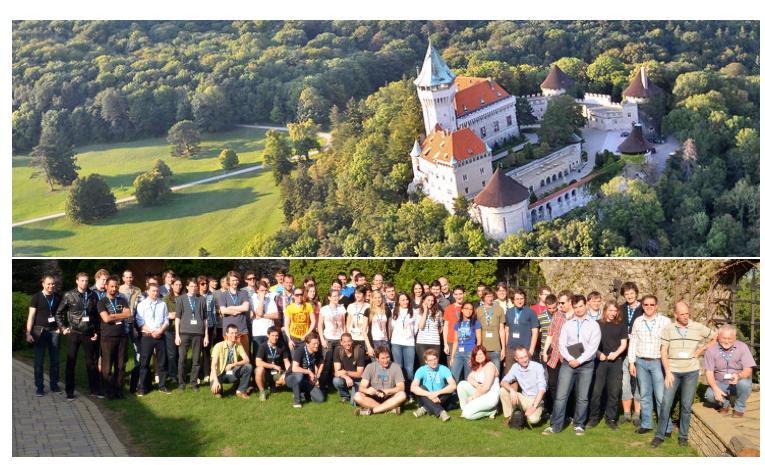

Figure 4: Top: The venue of CESCG, Smolenice castle by $M$. Švec. Bottom: Photo of the participants in Smolenice, 2013. 


\subsection{Schedule \& Organization during the year}

Any university or research centre can participate at CESCG with their BSc and MSc students. At the same time it becomes a member of the programme committee. There are no costs except for board and accommodation of the students. Partner institutions nominate talented students for the seminar three months in advance, i.e., in January. While finishing their research work, students are guided through the academic publishing process. Every submission receives detailed feedback from two or three domain experts. Programme committee members are instructed to be very patient and constructive when writing the reviews. In contrast to a real reviewing process, there is no rejection at CESCG. Quality assessment and control is trusted to the supervisors of students. The best 24 papers get a full presentation slot at the seminar; the rest is selected for a short presentation in a poster session. All submissions are printed in full length in the proceedings, regardless of the assigned presentation type. One week before the seminar, organisers give remote feedback on the presentation slides. Students also practice in front of a real audience at their home institutions. Preparation of a mandatory 30 seconds fast-forward is a completely new, valuable experience for the students.

Since 2015 the seminar format has been changing, with new features adding more interaction and dynamics. Opened by a fast-forward session of students and industry partners, the first day is focused on fascination by visual computing. The highlight is the EXPO - an interactive exhibition of innovative company products and university research from Central Europe, followed by industrial workshops and tutorials. Each year, around 15 exhibitors from the fields of gaming, 3D reconstruction, digital art, and human computer interaction attract almost 150 visitors (Figure 5). The remaining two seminar days are devoted to scientific presentations including two keynote speakers, and academic workshops. Student presentations are in a 15-minutes format. Posters are presented in 5 minutes each. At the closing ceremony the best papers, presentations and videos attached to the papers are awarded. This motivates students to prepare the material for the seminar in the best possible way.

Presenting workshop In the first morning, students learn about a general talk structure and interaction with the audience. They rehearse their fast-forwards so that everything runs smoothly at the opening. After each fast-forward, the audience is urged to provide feedback following the principles and structure explained earlier. In the evening, a pitching game is the ideal ice-breaker. Participants perform a 3minute pitch on a topic defined by two random CG-related words. During the game, students practice their improvisation and confidence in a controlled environment.

Storytelling workshop The second-day workshop is devoted to the structure of scientific papers and presentations. It follows general storyline principles of a mono-

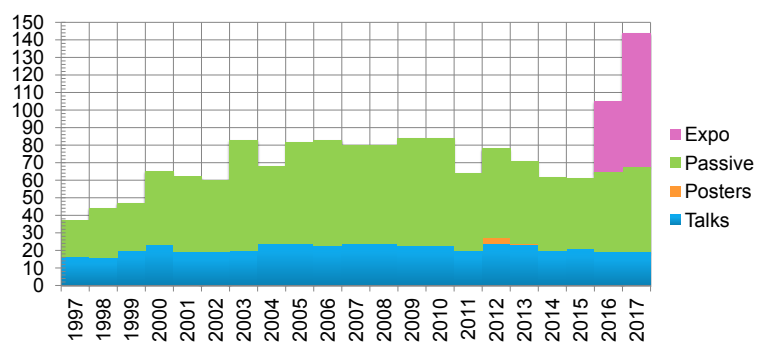

Figure 5: Attendance statistics of CESCG. Participants count (green) peeked 2003 - 2010. The number of presented papers (blue) is stable. Since 2016, EXPO attracts many visitors (purple).

myth [Cam49]. Assisted by mentors, participants assign keywords from their ongoing projects to the steps of the storyline. The familiar context of a student's own CG project stimulates analytic thinking and makes the practice easier. Students can directly use the assembled storylines later, when writing a thesis.

PhD workshop An informal fair of graduate positions has always been present. CESCG is very successful in connecting professors with their future $\mathrm{PhD}$ students. Casual networking often ends up discussing a project topic. Motivation for scientific careers is also part of the official programme. Professors introduce visual computing curricula and academic life styles across various universities and countries.

\subsection{Experience gained}

The high quality of student submissions is achieved by excellent, but also time-consuming guidance of their local supervisors. Unfortunately, if they invest too much effort and reach a certain quality, they often skip CESCG and submit directly to a peer-reviewed journal or conference. The scientific benefits are clear, but being not mutually exclusive, a prior CESCG experience is very important for students from the educational point of view. The seminar is classified as non-peer-reviewed since students only receive feedback, but no rejection is possible. The work can be resubmitted to most peer-reviewed journals and conferences. For a student seminar, the scientific impact of CESCG is strong. From 1997 to 2015 there were 411 CESCG papers, $55 \%$ of them got cited at least once. The most cited paper [Kör03] achieved 227 citations so far. The average number of citations per paper is 2.89 .

The main seminar goal - promotion of academic and research careers - is more difficult to quantify. The scientific records of all 484 authors of all 411 CESCG papers were investigated using various search engines. Annually, 10 - 15 of them enrol for a graduate study (Figure 6). Since 1997, it makes 222 in total. Some of the participants from the 


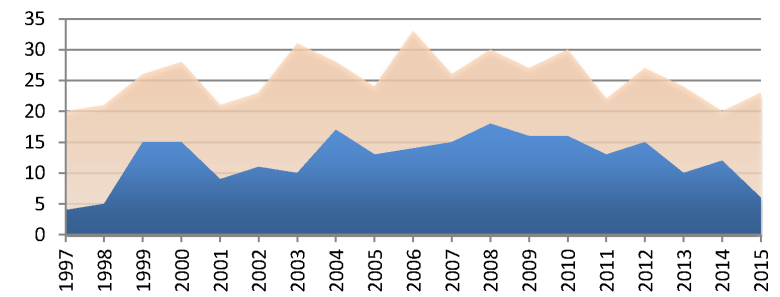

Figure 6: The count of authors who pursued a graduate study after the CESCG (blue) compared to the total number of authors for the respective year (orange).

early years are now professors sending their students to the CESCG to form the next generation of visual computing researchers.

Global visibility is important for funding agencies and sponsors. All published materials and information for students are available at the seminar webpage (http://cescg.org). A Youtube channel (http://bit.ly/1MZ85em) is the most important social medium. Improved marketing and branding is one of the important tasks for the future. Over 20 years, the format of CESCG has developed to a successful and respected event for undergraduate students. Maintenance of quality and financial stability will continue to be the most important tasks for the future organisers. Further improvements will be for sure necessary to reflect the evolution of society and technological advances. There is great potential to grow beyond the Central European region, thus all are invited to become part of the CESCG family.

\section{Summary and concluding remarks}

In this paper we described educational experiments that tackled problems in Computer Graphics (CG) education related 1) to arts and how it can be introduced in technicallyoriented CG courses, 2) to the question whether or not a visualisation course in game development curricula would be advantageous and 3) to the role of research-oriented activities in undergraduate CG curricula. These experiments consisted in courses and an extra-curricular seminar each attempting to provide a plausible answer to the previous problems.

Arts and game technologies are linked to CG. Traditionally, CG productions are a kind of collaboration between artists and CG experts, in which artists are learning some CG basics that they can use in their creative process. We described an art and graphics design course that conversely immersed science students into the field of art. This course showed that in many projects, art and CG science have come closer together. In particular, CG students have been able to design and develop new graphics tools for artists in close cooperation with them. The experiment demonstrated that science students can better understand the requirements of artists, so these new tools are of high quality and well-tuned to artistic needs.

The visualisation course in game development introduces an emphasis on visual analytics, scientific and information visualisation for a game development programme. This experiment showed that teaching visualisation in games can indeed be relevant for students. But it also showed that distinguishing such a course from traditional visualisation courses, for example by providing more concrete case studies in games, is necessary. What would be the best and most relevant case studies remains thereby an open issue that needs to be tackled in future works.

We also showed that bringing undergraduate students into research processes that are more usually experienced by postgraduate students proved to be an effective approach. The undergraduate collaborative research project in computer graphics and animation of the NCCA provides students with skills to be able to develop a software artefact solving a CG research problem, not only by providing the software but also by delivering a report in the form of an academic paper. It has shown that this further engages students that would otherwise be disengaged due to lack of challenge. The fact that the course has led to some conference submissions to established CG conferences, also showed that integrating research components into curricula can serve as an incentive for faculty members to become involved. The relevance of research components in an undergraduate programme has also been confirmed by the annual Central European Seminar on Computer Graphics that we described. Integrating a research component at undergraduate level remains however challenging. Methods to increase the interest and availability of supervisors, which is a key point for research related education activities, need to be further explored. Indeed, engaging undergraduate students in research is primarily constrained by the interest of faculty members. Designing novel courses that increase this interest makes sense.

Computer Graphics is a rapidly evolving Computer Science field. It is holding a more and more central place in our everyday lives. Beyond the more conventional CG-related fields of game development and visual effects for media productions, that we discussed in this paper, CG is steadily introducing novel application domains like recently computer assisted fabrication and computational photography. Maintaining relevant courses for teaching CG, in the light of these novel and emerging applications, is a key challenge for future research in CG education and raises a number of questions, such as: should novel applications systematically be integrated into CG curricula, and if yes, how can links with the corresponding scientific fields be created? How can we evaluate the success of these courses given the specificities of $\mathrm{CG}$ and related fields? 


\section{Acknowledgements}

The authors of section 3. Arts for Computer Graphics Students wish to thank the Grant Agency of the Czech Technical University in Prague, grant No. SGS16/237/OHK3/3T/13 (Research of Modern Computer Graphics Methods) for its support. The author of section 4. Visualisation in a Game Development Curriculum would like to thank all students and colleagues at Blekinge Institute of Technology (BTH) and Tobii that have contributed towards the development of the Visualisation course.

\section{References}

[AAF16] Anderson E. F., Adzhiev V., Fryazinov O.: Aiming High: Undergraduate Research Projects in Computer Graphics and Animation. In EG 2016 - Education Papers (2016), Santos B. S., Dischler J.-M., (Eds.), The Eurographics Association. doi:10.2312/eged.20161021.6,7

[Agr07] AgraWAla M.: Cs 294-10 fall '07 visualization. http://vis.berkeley.edu/courses/ cs294-10-fa07/wiki/index.php/Main_Page, 2007. 4

[ALA*10] Andersen E., LiU Y.-E., Apter E., BoucherGenesse F., POPOVIĆ Z.: Gameplay analysis through state projection. In Proceedings of the Fifth International Conference on the Foundations of Digital Games (New York, NY, USA, 2010), FDG '10, ACM, pp. 1-8. doi:10.1145/1822348. 1822349. 2

[AlFA15] Alvarez losada J., Fryazinov O., AnderSON E. F.: Real-time fluids - optimizing grid-based methods. In Proceedings of SIGRAD 2015: 36th annual conference of the Swedish Computer Graphics Association (2015), Linköping University Electronic Press, pp. 5355. URL: http://www.ep.liu.se/ecp/article. asp? is sue $=120 \&$ volume $=$ \&article $=015.6,7$

[APH*12] Anderson E. F., Peters C. E., Halloran J., Every P., Shuttleworth J., Liarokapis F., LANe R., RICHARDS M.: In at the deep end: An activity-led introduction to first year creative computing. Computer Graphics Forum 31, 6 (2012), 1852-1866. doi:10.1111/j.1467-8659.2012. $03066 . \mathrm{X.} 6$

[BA06] BALCISOY S., AYITER E. E.: Trans-disciplinary avenues in education: Computing and art. In Technologies for E-Learning and Digital Entertainment, First International Conference, Edutainment 2006, Hangzhou, China, April 16-19 (2006), pp. 80-89. 2

[BBD*10] BALdwin D., Brady A., Danyluk A., AdAms J., LAWRENCE A.: Case studies of liberal arts computer science programs. Trans. Comput. Educ. 10, 1 (2010), 4:1-4:30. doi : 10.1145/1731041.1731045.2,7

[BEJK12] Bowman B., ElmQvist N., Jankun-Kelly T. J.: Toward visualization for games: Theory, design space, and patterns. IEEE Trans. Vis. Comput. Graph. 18, 11 (2012), 19561968. 2

[Cam49] Campbell J.: The Hero with a Thousand Faces. Princeton University Press, Princeton, NJ, 1949. 8

[CC10] CoOper S., Cunningham S.: Teaching computer science in context. ACM Inroads 1, 1 (2010), 5-8. doi : 10.1145 / 1721933.1721934. 6

[CD02] Chalmers A., Dalton C.: Visual perception in computer graphics education. In Eurographics-ACM SIGGRAPH Workshop on Computer Graphics Education, CGE 02, Bristol University, UK, July 6-7 (2002). 2
[CMA10] Comninos P., McLoughlin L., Anderson E. F.: Educating technophile artists and artophile technologists: A successful experiment in higher education. Computers \& Graphics 34, 6 (2010), 780-790. doi:10.1016/j.cag.2010.08. $008.2,6$

[CWF*10] Carter J., White S., Fraser K., Kurkovsky S., MCCREESH C., WIECK M.: ITiCSE 2010 working group report motivating our top students. In Proceedings of the 2010 ITiCSE Working Group Reports (2010), ITiCSE-WGR '10, pp. 29-47. doi:10.1145/1971681.1971685. 6

[Dom15] DомIK G.: Acm siggraph curriculum for visualization (editor: G. domik, prepared by the acm siggraph education subcommittee on education for visualization). http://Www . uni-paderborn.de/cs/vis, 2015. 2

[Ebe00] EBER D. E.: Computer graphics curricula in the visual arts. Computers \& Graphics 24, 6 (2000), 919-923. Calligraphic Interfaces: towards a new generation of interactive systems. 2

[Eyi11] Eyitayo O. T.: Do students have the relevant ict skills they need to do their research projects. In Proceedings of the 2011 Conference on Information Technology Education (2011), SIGITE'11, pp. 287-292. doi : $10.1145 / 2047594$. 2047668.2

[FCD*15] Feltwell T., Cielniak G., Dickinson P., KiRMAN B. J., LAWSON S.: Dendrogram visualization as a game design tool. In Proceedings of the 2015 Annual Symposium on Computer-Human Interaction in Play (New York, NY, USA, 2015), CHI PLAY '15, ACM, pp. 505-510. 2

[Haz14] HAZZARD E.: Data visualization in games. http://vasir.net/blog/game-development/ data-visualization-in-games, 2014. 2

[HFSK00] Hauser H., Ferko A., Szirmay-Kalos L. (Eds.): CESCG '97 - '99. Austrian Computer Society, 2000. 2, 7

[IIFW16] ILČík M., IlČíkovÃĄ I., Ferko A., Wimmer M.: 20 Years of the Central European Seminar on Computer Graphics. In EG 2016 - Education Papers (2016), Santos B. S., Dischler J.-M., (Eds.), The Eurographics Association. doi : 10.2312 / eged. 20161022.7

[Kör03] KöRTGEN M.: 3D Shape Matching with 3D Shape Contexts. In Proceedings of the $7^{\text {th }}$ Central European Seminar on Computer Graphics CESCG'03 (Apr. 2003), Vienna University of Technlonogy, Austria. 8

[KWP14] Kriglstein S., Wallner G., Pohl M.: A user study of different gameplay visualizations. In Proceedings of the SIGCHI Conference on Human Factors in Computing Systems (New York, NY, USA, 2014), CHI '14, ACM, pp. 361-370. 2

[LFB*13] LUKÁČ M., FIŠER J., BAZIN J.-C., JAMRIŠKA O., SORKINE-Hornung A., SÝKORA D.: Painting by feature: Texture boundaries for example-based image creation. ACM Transactions on Graphics (Proceedings of SIGGRAPH 2013) 32, 4 (2013), 116:1-116:8. doi:10.1145/2461912.2461956. 4

[LH11] Livingstone I., Hope A.: Next Gen: Transforming the UK into the World's Leading Talent Hub for the Video Games and Visual Effects Industries. Report produced for the National Endowment for Science, Technology and the Arts, 2011. URL: http://www. nesta.org.uk/ publications/next-gen. 2, 6

[MBWMN14] Mirza-Babaei P., WAllner G., McAllister G., NACKE L. E.: Unified visualization of quantitative and qualitative playtesting data. In CHI ' 14 Extended Abstracts on Human Factors in Computing Systems (New York, NY, USA, 2014), CHI EA '14, ACM, pp. 1363-1368. 2 
[MeNS11] Moura D., El NASR M. S., Shaw C. D.: Visualizing and understanding players' behavior in video games: Discovering patterns and supporting aggregation and comparison. In Proceedings of the 2011 ACM SIGGRAPH Symposium on Video Games (New York, NY, USA, 2011), Sandbox '11, ACM, pp. 1115. 2

[MMA17] Madges G., Miles I., Anderson E. F.: AnimDiff: Comparing 3D Animations for Revision Control. In EG 2017 - Short Papers (2017), Peytavie A., Bosch C., (Eds.), The Eurographics Association. doi:10.2312/egsh.20171007.7

[MPA16] Minor T., Poncelet R. R., Anderson E. F.: Skyglow: Towards a Night-time Illumination Model for Urban Environments. In EG 2016 - Posters (2016), Magalhaes L. G., Mantiuk R., (Eds.), The Eurographics Association. doi : 10.2312 / egp. 20161055. 6,7

[NDC13] NASR M., DraChen A., Canossa A.: Game Analytics: Maximizing the Value of Player Data. Springer Science \& Business Media, 2013. 2, 5

[OC00] Ollila M., CARling E.: Bringing art into computer graphics education. Computers \& Graphics 24, 4 (2000), 617622. 2

[O1199] Ollila M.: Combining art and mathematics in computer graphics education. In Eurographics-ACM SIGGRAPH Workshop on Computer Graphics And Visualization Education, GVE'99, Coimbra, Portugal, July 3-5 (1999), pp. 105-109. 2

[Shn16] SHNEIDERMAN B.: Teamwork in computing re- search. Commun. ACM 59, 8 (2016), 30-31. doi : $10.1145 /$ 2955110.2, 6

[SSZ16] Svobodova L., Slavik P., Zara J.: A Trip to Arts for Computer Graphics Students. In EG 2016 - Education Papers (2016), Santos B. S., Dischler J.-M., (Eds.), The Eurographics Association. doi:10.2312/eged.20161019.3,4

[Sun16] Sundstedt V.: A Visualisation Course in a Game Development Curriculum. In EG 2016 - Education Papers (2016), Santos B. S., Dischler J.-M., (Eds.), The Eurographics Association. doi: 10.2312 /eged.20161020.2,4, 5

[The13] Computer science curricula 2013 - curriculum guidelines for undergraduate degree programs in computer science. https://www.acm.org/education/ CS2013-final-report.pdf, 2013. 2

[WFSKH06] Wimmer M., Ferko A., Szirmay-Kalos L., HAUSER H. (Eds.): CESCG 2000 - 2005 Best Paper Selection. Austrian Computer Society, 2006. 7

[WKG*14] Wallner G., Kriglstein S., Gnadlinger F., Heiml M., Kranzer J.: Game user telemetry in practice: A case study. In Proceedings of the 11th Conference on Advances in Computer Entertainment Technology (New York, NY, USA, 2014), ACE'14, ACM, pp. 45:1-45:4. 2

[WS06] Walker E. L., Slotterbeck O. A.: Integrated research components: A practical and effective alternative to senior projects. J. Comput. Sci. Coll. 22, 1 (2006), 72 83. URL: http://dl.acm.org/citation. cfm?id= 1181811.1181821.2 